\title{
Measuring Racial Climate in Schools of Social Work: Instrument Development and Validation
}

\section{Cathy King Pike}

Objective: This article reports the initial validation of an instrument designed to measure racial climate in programs and schools of social work. Method: An unduplicated sample of students from one school of social work $(\mathrm{N}=182)$ responded to a survey of racial climate. Psychometric analyses were computed to determine the reliability and validity of the instrument's scales. Results: The scales attained high levels of internal consistency reliability, had a stable factor structure for the items as they were hypothesized, and performed well in preliminary analyses of convergent construct and known-groups validity. Conclusions: The results provided initial evidence of internal consistency reliability and content, construct, factorial, and known-groups validity.

As the 21st century unfolds, the composition of the United States will be characterized by increasing racial and ethnic diversity. For instance, Buford (1999) wrote that 10 years ago business was primarily White and male but that this is changing rapidly with White males projected in the future to make up only $15 \%$ of entrants into business. Kipp (1998), in forecasting demographic changes in relation to the Pell Grant program, noted that by the year 2010 approximately $32 \%$ of the U.S. population will be composed of a variety of ethnic and minority groups.

Other professions, including education and business, are intensifying their responses to these forecasts by developing and enhancing courses or training in culturally sensitive practice (Buford, 1999; Kailin, 1998; Nagel, 1998). Social work and the other helping professions, on the other hand, have a history spanning at least from the Progressive Era (1898-1918) of examining the influence of race on a number of aspects as these relate to clients of racial or ethnic diversity (Carlton-LaNey, 1999). Social work and the helping professions have continued to examine race as it affects the family and family relationships, the workforce and workplace interactions, and culturally relevant practice with clients (Anderson, 1998; Baer, 1999; Copeland, 1996; Gant, 1996; Goodman, Getzel, \& Ford, 1996; Herz \& Ferguson, 1996; Hollingsworth, 1998; Poindexter \& Linsk, 1999; Schiele, 1996; Stevens, 1998). A strengths-oriented approach to practice with clients of diversity became more prevalent over time as more information emerged about cultural and racist influences on the well-being of individuals and families (Carter, 1997; Greif, Hrabowski, \& Maton, 1998; Haight, 1998; Harvey \& Rauch, 1997; Scannapieco \& Jackson, 1996; Schiele, 1996; Swigonski, 1996).

In social work, the Council on Social Work Education (1997) required that baccalaureate and master's programs of social work integrate content on race and ethnicity (along with other cultural groups), populations at risk, and the promotion of social and economic justice. To accomplish this, teachers typically have used lecture materials, reading assignments in required texts, outside reading assignments, classroom exercises, papers, and examinations. More 
frequently, cultural self-assessments are being used to help students understand their own contextual influences and how those may be similar or different across racial and ethnic groups (Lum, 1999; Mason, 1995; Okum, Fried \& Okum, 1999; Singelis, 1998).

The importance of student self-assessments in understanding their own cultural contexts and ultimately those of others cannot be underestimated. However, social work has lagged behind other fields in assessing its own educational context (or climate) in promoting tolerance and acceptance of racial, ethnic, and cultural diversity. This omission is related to a second requirement of the Council of Social Work Education (1997), that social work programs and schools evaluate the extent to which they achieve their goals and objectives (Buchan, 1991; Hull, Mather, Christopherson \& Young, 1994). However, the literature review for this research identified no report of a published instrument that is used in social work to examine the racial climates of programs and schools. It stands to reason that if it is important for students to examine their own cultural contexts and how those contexts provide them privilege and specific world views, it is also important for programs and schools to understand the racial climate they provide to students.

Allport's (1954) classic work emphasized prejudice not only at the individual psychological level but also at historical, socio-cultural, situational, and interactional levels of analysis. Later, Blumer (1958) described the group position theory of prejudice. This theory seeks to explain the relative positioning of groups based on a normative framework of racial identities. In addition, Blumer (1955) proposed that group positions become institutionalized over time and that prejudice is a defensive mechanism that is used to maintain group position.

Several studies have focused on respondents' evaluations of prejudice toward their groups versus that which they feel as individuals (i.e., examinations of group level versus individually felt prejudice or discrimination). These studies have examined the perceptions of employed women, South Asian women, Haitian women, impoverished single mothers, university women, impoverished African American men, gays and lesbians, African American Harvard University male and female undergraduates, and female Harvard University undergraduates (Bobo, 1999; Moghaddam, Stolkin \& Hutcheson, 1997; Olson, Roese, Meen \& Robertson, 1995; Postmes, Branscombe, Spears \& Young, 1999; Ruggiero, 1999; Ruggiero \& Taylor, 1994; Taylor, Wright, \& Porter, 1994; Taylor, Wright, \& Ruggiero, 1991; Zanna, Crosby \& Loewenstein, 1987). These studies consistently found that minority groups tended to perceive more prejudice directed toward their groups than toward themselves. These findings concur with Allport's (1954) suggestion that members of minority groups may deny or de-emphasize the existence of personal experiences of prejudice or discrimination.

A review of the literature revealed instruments developed and used by three professions and organizations to study racism or racial climate. Green (1995) developed a scale to measure African American women's experiences of racism in the medical community. Included in the scale were 20 items, each measuring from 1 to 4 on a Likert-type scale. The items were directed at group level discrimination rather than the individual experiences of the women. Scale reliability coefficients were reported as .88 and .91. The author reported only a limited face validity examination and no factor analyses or other psychometric testing. 
Baughan (1992) developed an instrument to measure students' perceptions of the racial climate at Prince George's Community College. His survey contained several sections that examined students' perceptions about American society; knowledge of the percentage of minority students, faculty, administration, and staff; knowledge about changes over time in the racial makeup of the above categories; perceptions of race and ethnic group relations; overall perceptions about race relations; and perceptions about meeting their educational goals. All of the scales' items were measured from 1 to 5. However, different scales had variously worded anchors (e.g., strongly agree to strongly disagree for the scale measuring perceptions of racism in American society and increasing fast to decreasing fast for the scale measuring racial makeup. The report provided no information about examinations of reliability or validity for these scales.

The military has been most notable in its consistent attention to the measurement of racism and racial climate, particularly during the 1970s. During that period, four instruments were developed to measure racism, discrimination, racial attitudes, and backlash racial attitudes (Borus, Stanton \& Doud, 1972; Hiett, McBride \& Fiman, 1978; Nordlie \& Thomas, 1974; Stoloff, Lockman, Allbritton \& McKinley, 1972). The most recent instrument, the Racial Attitudes and Perceptions Survey (Hiett et al., 1978), combined many of the items from the earlier three instruments. This comprehensive instrument measures perceptions of military personnel in four content areas: perceptions of discrimination against African Americans, attitudes toward racial interaction, feelings of reverse racism (backlash), and racial climate. The instrument measures discriminatory behaviors and tension levels as perceived by military personnel and uses a combination of behavioral and attitudinal indicators. All scales use 5-point Likert-type scaling with either a strongly agree to a strongly disagree or a frequency of occurrence continuum. All of the scales except the racial climate scale use items that are phrased at the group level. The items of all of the scales are highly focused on issues related to the military. Coefficient alphas for the scales ranged from .74 to .92. Test-retest reliability coefficients ranged from .66 to .76. The scales exhibited good evidence of construct validity in psychometric analyses.

The objective of the current research was to develop an instrument that measures with satisfactory reliability and validity racial climate within programs and schools of social work and that focuses on students' perceptions of racial climate at both the faculty and student levels.

\section{Method}

\section{Informed Consent}

An informed consent form was developed for the study and distributed to all respondents. The informed consent form advised students about the nature of the research, along with the risks and benefits associated with the research. In addition, respondents were informed that their participation was entirely voluntary, their personal anonymity was guaranteed, and no information would be reported that would identify a specific course section. To further protect students' anonymity, they were asked not to sign the consent form and told that their completed scan sheets would serve as their agreement to participate in the research. Students were advised 
of how to contact the author of the research, should they experience significant levels of discomfort as a result of the research.

\section{Sample}

The sampling goal for this research was to sample without duplication all on-campus students, including part-time, full-time, and advanced-standing students within one school of social work. To accomplish this, the sampling frame included all sections of a foundation-level course and those sections of two advanced-year courses that represented the two concentrations within the school. This strategy prevented duplication while assuring that all current students had an opportunity to participate in the research.

Survey packets were designed for each section of the courses. These packets included a letter of request to participate in the research, an informed consent form, questionnaires, scan sheets, and pencils. Members of the Master of Social Work Student Equity Task Force distributed either by campus mail or in person the packets to those faculty members who taught the course sections that comprised the sampling frame. Faculty members were asked to distribute the packets in their course sections. Completed surveys were returned to a college mailbox labeled specifically for the research.

\section{Measures}

The domain-sampling theory of instrument development was used for this instrument development. Item content identification proceeded with a review of racial climate indicators found in the literature and the development of indicators of racial climate that would relate well to social work education. The Racial Climate Inventory (RCI) contained two scales: a faculty scale that measured racial climate as it related to perceptions of racial climate evidenced by faculty and a student scale that measured racial climate among students in a school of social work. Racial climate was measured at the group level and was defined as students' subjective perceptions of how both faculty and their peers generally responded to issues and people of diversity. Both scales were written at the group level because the literature had identified a greater tendency for minority group members to perceive racial prejudice and discrimination at the group rather than the individual level. This focus made the instrument more sensitive in identifying racial prejudice and discrimination. For the faculty scale, particular attention was paid to identifying racial climate content as it related to classroom dynamics, how content on diversity was managed within the classroom, and the classroom environment. The student scale focused on racial climate as perceived by students both within and outside of the classroom environment. Because this school of social work is located in the South and the largest minority group were African Americans, the instructions asked students to focus on racial climate as it related to Euro-Americans and African Americans. However, to make the scale more useful for other schools of social work, the items were phrased using diversity phraseology in place of a specific ethnic group. The faculty scale contained 21 items, and the student scale contained 19 items. Scaling was accomplished by using a 0 to 9 response scale with anchors that ranged from not a problem to severe problem. The appendix provides a list of the items for each scale. 
In addition to the development of the RCI, three additional variables were included for use in psychometric analyses that related to the faculty and student scales. These variables asked respondents to (a) rate the extent to which recent African American faculty resignations from the school affected their perceptions about racial climate at each of the faculty and student levels and (b) rate the extent to which the recent formation of an African American student association affected their perceptions about racial climate at the student level.

The purpose in using these three variables arose from faculty concerns about recent events that might have influenced students' perceptions of racial climate within the school. The three variables were expected to correlate with both the faculty and student scales. The two questions about the extent to which recent African American resignations from the school affected perceptions of racial climate at the faculty and student levels were expected to be moderately and positively correlated with the two scales because some faculty and students had expressed concerns about the racial climate in the school after these resignations. The remaining question about the formation of the African American student association was expected to have a low positive correlation with the two scales because this issue did not seem to be as controversial as the faculty resignations.

\section{Results}

\section{Response Rates}

Completed survey packets were received from 11 of 20 course sections, for an overall response rate by course section of 55\%. Some faculty members noted that the timing of the survey (toward the end of the semester) prevented them from being able to take class time for students to complete the survey. There was a total of 340 students in all course sections. The number of student responses received for each section ranged from 14 to 21, with most sections containing 18 to 19 responses per section $(N=182)$. A total of 158 students were enrolled in sections for which no survey packets were returned. The approximate individual response rate was 54\%. Although a higher response rate for this study would have been preferred, practical considerations prevented a second sampling of those course sections where students were unable to participate due to time limitations. The achieved response rate was acceptable for survey research.

\section{Descriptive Statistics}

Responding to the survey questions on racial and ethnic background ( $\mathrm{N}=172)$ were $32(18.6 \%)$ African American students, 125 (72.7\%) Euro-American students, and 15 (8.7\%) students representing other ethnic groups. Of the student responses, 47 (27.3\%) reported that they belonged to an ethnically diverse group. No other socio-demographic variables were collected due to students' concerns about anonymity. 
Frequencies were generated for all of the items for the faculty and student scales. The medians for all of the faculty scale items ranged from 0 to 2, where 0 was defined as not a problem and 2 was two points more than not a problem and one point less than a slight problem (measured as a 3 ). The medians for the student scale items were slightly higher than those for the faculty scale and ranged from 1 to 3. The median for the summed faculty scale items was $21.0(x=31.61)$, and the median for the summed student scale items was $32.5(x=41.70)$. Both the faculty and student scales were skewed toward the right, with the modal response for each item of both scales equaling 0 .

The medians and means were examined for the three additional variables that examined the influence of recent faculty resignations and the formation of an African American student association on perceptions of racial climate. The median for Question 43 (the extent to which the resignations had influenced their perceptions of racial climate at the faculty level) was 5.0 (between slightly and moderately), and its mean was 4.81. The median for Question 44 (the extent to which the resignations had influenced their perceptions of racial climate at the student level) was $4.0(x=4.37)$. The median for Question 45 (the influence of the formation of the African American student association on perceptions of racial climate at the student level) was $4.0(x=4.12)$. These three variables were more normally distributed than the faculty and student scales. The item scores ranged from 0 to 9, with standard deviations ranging from 3.36 to 3.46.

\section{Examinations of Internal Consistency}

Estimates of internal consistency reliability were computed for each of the scales as they were hypothesized during scale development. The faculty scale yielded an alpha of .95, with no item yielding a higher alpha if deleted. The standard error of measurement for the faculty scale was 7.76, a very low level of error measurement for a scale with a possible range of 0 to 189 . The student scale yielded an alpha of .96, again with no items deleted to yield a higher alpha. The standard error of measurement for the student scale was 7.75, again a very low level of error measurement for this scale with a possible range of 0 to 171. As a result of these analyses, all items as originally written for the two scales were retained. Table 1 provides additional information related to the estimates of internal consistency.

\section{Evaluation of Factorial Structure}

Two factor analyses were computed for all items comprising the faculty and student scales. Principal components factor analyses with Promax rotations were used in these computations. Two tests of the assumptions of factor analyses were conducted. They were the Kaiser-MeyerOlkin measure of sampling adequacy and the Bartlett's test of sphericity. The Kaiser- MeyerOlkin measure of sampling adequacy can range from 0.0 to 1.0 and measures the extent to which the variables in a factor analysis can be predicted without error by the remaining variables. Any coefficient .80 or above is considered meritorious, with a 1.0 indicating perfect errorless measurement. The Bartlett's test of sphericity is a statistical test of the significance of correlations between the variables in a factor analysis. The Kaiser- Meyer-Olkin measure of sampling adequacy was .911, and the Bartlett's test of sphericity was significant $(\chi 2=6351.54, p$ 
$<.001$ ). These analyses indicated that the items were sufficiently correlated for use in factor analyses.

Table 1

Reliability Statistics for the Faculty and Students Scales

\begin{tabular}{lccccc}
\hline Scale & $\mathrm{n}$ & $\overline{\mathrm{x}}$ & SD & SEM & $\alpha$ \\
\hline Faculty & 151 & 33.01 & 34.14 & 7.76 & .95 \\
Student & 156 & 41.88 & 36.66 & 7.75 & .96 \\
\hline
\end{tabular}

Note: Missing data were deleted listwise. Results are rounded to two decimal places.

The initial analysis was conducted to examine the likely number of factors that represented the collection of items. This initial analysis extracted six factors. The screen plot indicated a steep grade between the first and second factors, with a dramatic leveling off after this point. The first factor accounted for $47.28 \%$ of the total variance, followed by a second factor that contained $7.85 \%$ of the total variance. The third factor accounted for less than $5.4 \%$ of the total variance, and the remaining factors ranged from $2.91 \%$ to $4.55 \%$. The first five factors shared moderate positive correlations, and the sixth factor had low positive correlations with all other factors. An examination of the factors revealed that both faculty and student items were contained in the last four factors. It appeared that these factors were composed of items from each scale that measured similar features but at the two different group levels. Factors containing less than $5 \%$ to $6 \%$ of the variance often are considered to be trivial factors that are most likely composed of error measurement factors rather than substantive factors (Nunnally \& Bernstein, 1994).

A second factor analysis was conducted with a specified two-factor solution based on the conceptual and theoretical issues for the scales as hypothesized. The primary loadings for the structure matrix for each factor were good, ranging from .565 to .854. All of the items loaded as hypothesized on the factor for which they were written except for four items in the student scale that loaded slightly more heavily on the faculty scale. These were Items 30, 31, 32, and 33. Again, these four items measured racial bias (both negatively and positively oriented bias) and were similar to some items from the faculty scale. Because of theoretical considerations, these four items were retained as student scale items. The first factor accounted for $47.28 \%$ of the total variance, and the second factor accounted for $7.85 \%$ of the total variance, for a total of $55.13 \%$ of the variance. The two factors were correlated at .673, indicating that similar but separate constructs are measured by the scales. Table 2 provides the structure matrix for the final factor analysis. 
Table 2

Structure Matrices for Items in the Radical Climate Inventory

\begin{tabular}{|c|c|c|}
\hline Item Number & Faculty & Student \\
\hline 6 & .82 & .62 \\
\hline 18 & .80 & .59 \\
\hline 21 & .78 & .62 \\
\hline 16 & .78 & .60 \\
\hline 5 & .76 & .52 \\
\hline 3 & .76 & .47 \\
\hline 13 & .75 & .61 \\
\hline 15 & .74 & .60 \\
\hline 11 & .74 & .48 \\
\hline 12 & .73 & .63 \\
\hline 33 & .73 & .62 \\
\hline 1 & .72 & .49 \\
\hline 17 & .71 & .51 \\
\hline 4 & .70 & .58 \\
\hline 32 & .69 & .60 \\
\hline 31 & 69 & .59 \\
\hline 8 & .68 & .39 \\
\hline 7 & .67 & .32 \\
\hline 14 & .65 & .36 \\
\hline 2 & .62 & .38 \\
\hline 20 & .60 & .45 \\
\hline 9 & .59 & .31 \\
\hline 19 & .59 & .56 \\
\hline 10 & .58 & .25 \\
\hline 30 & .57 & .49 \\
\hline 24 & .59 & .85 \\
\hline 25 & .52 & .85 \\
\hline 40 & .69 & .84 \\
\hline 26 & .46 & .82 \\
\hline 38 & .67 & .81 \\
\hline 22 & .39 & .81 \\
\hline 23 & .34 & .80 \\
\hline 39 & .53 & .79 \\
\hline 36 & .66 & .78 \\
\hline 35 & .58 & .73 \\
\hline 41 & .50 & .73 \\
\hline 34 & .69 & .73 \\
\hline 28 & .59 & .73 \\
\hline 37 & .59 & .69 \\
\hline 27 & .46 & .61 \\
\hline
\end{tabular}

Note: Decimals are rounded to hundredths. 
Table 3

Examinations of Convergent Construct Validity

\begin{tabular}{lll}
\hline Variable & Faculty & Student \\
\hline $\begin{array}{l}\text { Extent to which perceptions of racial climate among faculty } \\
\text { has been influenced by recent faculty resignations }\end{array}$ & $.515^{* *}$ & $.415^{* *}$ \\
$\begin{array}{l}\text { Extent to which perceptions of racial climate among students } \\
\text { has been influenced by recent faculty resignations }\end{array}$ & $.461^{* *}$ & $.419^{* *}$ \\
$\begin{array}{l}\text { Extent to which the formation of the African American student } \\
\text { association has influenced perceptions of racial climate I } \\
\text { among students }\end{array}$ & $.305^{* *}$ & $.316^{* *}$ \\
\hline$* p<.01$ (one-tailed). & &
\end{tabular}

\section{Preliminary Examinations of Construct and Known-Groups Validity}

Pearson correlations were computed for Variables 43 to 45 and the total scores for the faculty and student scales to examine the convergent construct validity of the faculty and student scales. Variables 43 and 44 were expected to have moderate positive correlations with the faculty and student scales, indicating related but different constructs. Variable 45 was expected to have a low positive correlation with the scales. The correlations of Variables 43 and 44 with the faculty and student scales ranged from .415 to .515. The correlations of Variable 45 with the faculty and student scales were .305 and .316, respectively. These results provided some preliminary support for the convergent construct validity of the faculty and student scales. Table 3 provides information about these correlations.

To further examine the validity of the two scales, descriptive statistics were generated to provide an initial evaluation of differences by racial or ethnic group. The median for Euro-American students for the faculty scale was $15.0(x=20.12$, $S D=19.33)$ and for the student scale was 26.0 $(\mathrm{x}=32.66, \mathrm{SD}=28.74)$. African American students had a median of $54.5(\mathrm{x}=60.25, \mathrm{SD}=$ 38.82) and $59.0(x=62.53, \mathrm{SD}=39.53)$, respectively, on the faculty and student scales. Persons representing other ethnic groups within the school had a median of $34.0(x=33.0, S D=28.21)$ and $40.0(x=46.07, S D=36.20)$ on the faculty and student scales, respectively. These descriptive statistics suggested that as expected, Euro-American students would have lower medians and means and smaller standard deviations for both scales than the students from other ethnic groups and African American students, who could be expected to be more sensitive to racial climate as it affected their race. Table 4 provides further information about these analyses.

Because the homogeneity of variance assumption was violated with this data, a Kruskal-Wallis test was performed (rather than an ANOVA) by ethnic group on mean ranks of scores for the faculty and student scales. Both analyses were significant (for faculty, $\chi 2=31.436, \mathrm{p}<.001$; for student, $\chi 2=16.072, \mathrm{p}<.001)$. A Ryan's follow-up test was computed to determine which of the three groups were significantly different (Siegel \& Castellan, 1988). This tests is similar to Tukey's honestly significant difference and other follow-up tests for ANOVAs and controls for the overall alpha level in the determination of critical values of the mean rank differences. The mean ranks of African American students on both the faculty and student scales were 
significantly higher than the mean ranks of Euro-American students. The mean ranks of African American students and students from other ethnic groups did not differ significantly from each other on either scale. In addition, the mean ranks of Euro-American students and those students representing other ethnic groups did not differ significantly on either scale.

Because the sample sizes for African American students and those students representing other ethnic groups were very small, outlier analyses were conducted to identify whether a few extreme scores had influenced the results of the Kruskal-Wallis and Ryan's tests. No outliers were identified as having scores that lay outside 2.5 standard deviations of the means for either scale. These results provide initial support for the known-groups validity of the faculty and student scales. However, further testing with larger samples of African American students and students from other ethnic groups is needed due to the small sample sizes of these two groups of students. In further testing with larger sample sizes, significance differences may be found between African American students and students from other ethnic groups.

\section{Discussion and applications to social work practice}

The RCI and the items as hypothesized for each scale performed well in this initial validation study. The two scales evidenced high levels of reliability, well above .90, and had low levels of measurement error. In the internal consistency reliability analyses, no items had to be deleted to yield a higher coefficient alpha. The factor analyses provided additional information about the scales' psychometric properties. With the exception of four items, all items loaded on their respective scales as hypothesized during instrument development. The factor analyses provided preliminary evidence of the content, factorial, and construct validity of the scales. The examinations of the correlations between the faculty and student scales and the three related variables also supported the convergent construct validity of the instrument. An initial examination of known-groups validity was conducted through the use of Kruskal-Wallis tests of scores on both scales by ethnicity. These tests and the follow-up examinations supported the known-groups validity of the instrument.

The RCI can be used by programs and schools of social work to examine racial climates at the faculty and student levels. The reliability estimates are certainly high enough for use by a single program, as evidenced with this study of a single program. In addition, the instrument should perform well for programs smaller than the program used for this validation study. Cohen and Cohen (1983) and Hudson (1982) suggested that coefficient alphas of .60 were sufficient for group research and that coefficient alphas of .80 were necessary for clinical decision making with regard to individuals. The high levels of reliability and good preliminary evidence of content, construct, and known-groups validity bodes well for the instrument's use in other educational racial climate studies. 
Table 4

Kruskal-Wallis and Follow-up Tests of Significant Differences by Race and Ethnicity

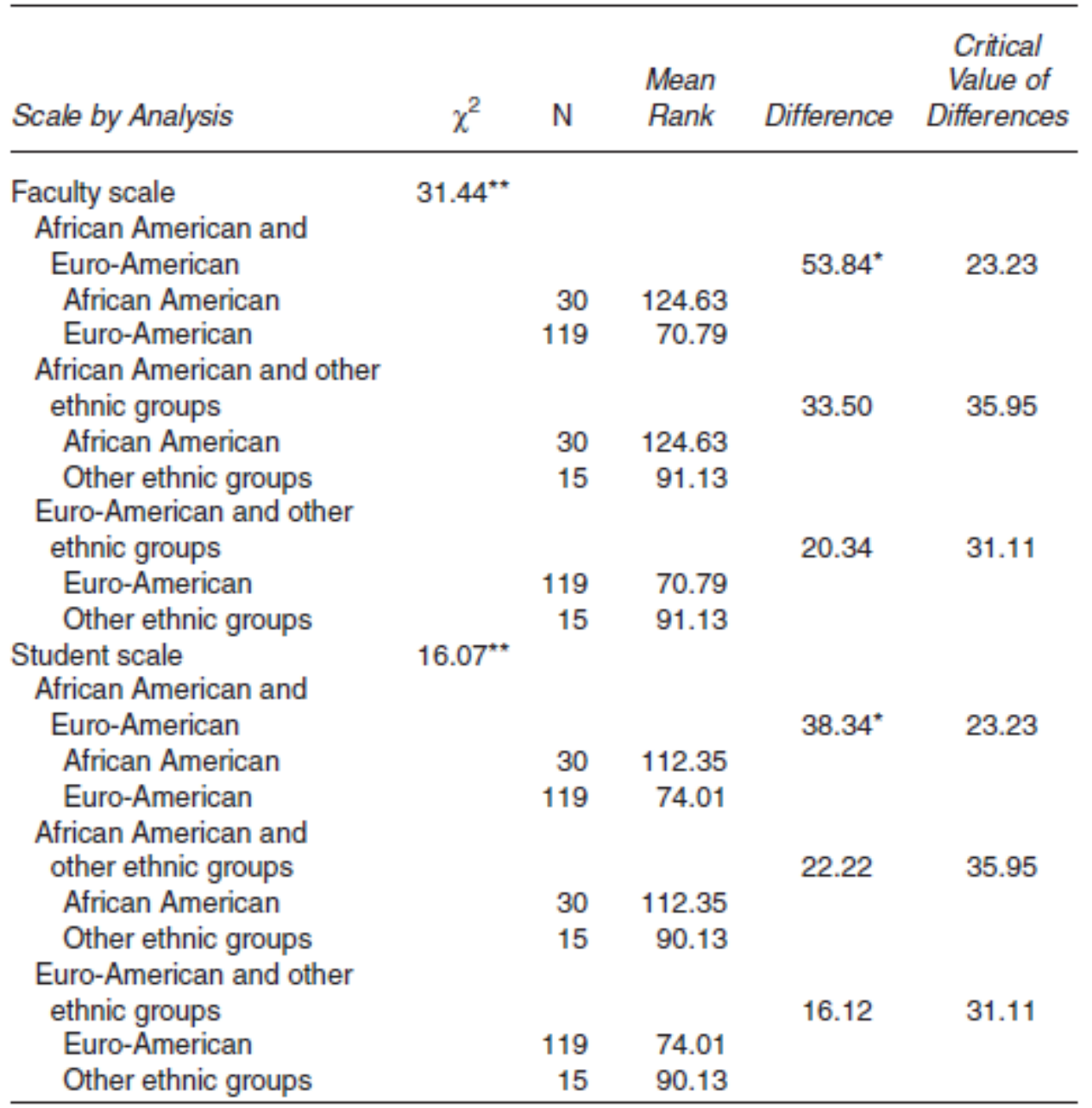

Note: The overall Kruskal-Wallis test is the $\chi 2$. The critical value of differences is obtained through the Ryan's follow-up test.*p $<.05$, significant differences among groups on the Ryan's follow-up test. ${ }^{* *} \mathrm{p}<$ .001 , significant differences in the two Kruskal-Wallis overall tests.

Additional research is needed to further evaluate the factorial stability and construct validity, particularly the convergent and discriminant construct validity, of the RCI. This study had a somewhat small sample size for psychometric analyses. It is possible, although not highly likely, that selection bias could have occurred in the examinations of known-groups validity. Further studies conducted in other programs and schools would provide knowledge about the instrument's stability across differing types of programs and schools, geographic locations, educational levels, and sizes of programs. The instrument should also be evaluated in studies where other ethnic groups comprise the largest minority group. This type of study would provide information about the extent to which the instrument can measure with satisfactory reliability and validity racial climate as it relates to groups other than African Americans.

Social work has an extensive history of attention to racism and its effects on individuals, families, groups, and social and political functioning. Accredited social work programs and schools must demonstrate how students develop cultural awareness and culturally competent 
practice (Council on Social Work Education, 1997). However, social work faculty should not neglect a crucial aspect of educating students about diverse populations, racism, prejudice, and discrimination. That crucial aspect of the educational environment is the racial climate a program or school provides. Without assessments of racial climate, faculty and administration are left with the same sort of guesswork about racial climate that students are warned against doing in practice through the use of single-system designs to monitor client progress and evaluate practice interventions. The RCI is a first effort to operationalize racial climate for programs and schools of social work.

\section{Appendix}

\section{Scale Items for the Racial Climate Inventory}

\section{$\underline{\text { Faculty Scale }}$}

1. Faculty respect for beliefs and opinions expressed by students of diversity.

2. Faculty use of slang terms to identify diverse populations.

3. Faculty use of culturally sensitive terms in describing diversity.

4. Faculty willingness to discuss diversity issues in the classroom.

5. Faculty willingness to allow students' challenges to culturally dominant perspectives in the classroom.

6. Faculty behaviors toward students of diversity that indicate a lack of respect for populations of diversity.

7. Faculty leniency in grading because of a student's racial diversity.

8. Faculty holding students of diversity to higher standards on assignments.

9. Faculty providing favorable treatment on late submissions because of a student's diversity.

10. Faculty holding students of diversity to lower standards on assignments.

11. Faculty addressing stereotypes related to diversity in the classroom when appropriate to course content or classroom situational demands.

12. Faculty facilitation of emotionally charged discussion about diversity in the classroom.

13. Faculty awareness of diversity issues related to course content.

14. Faculty use of jokes that are insulting to populations of diversity.

15. Faculty efforts to provide an inclusive environment in the classroom.

16. Faculty's inappropriate use of cultural stereotypes in teaching diversity content.

17. Faculty use of culturally offensive reading assignments related to diversity.

18. Faculty suggestions and help for students of diversity when needed.

19. Faculty efforts to inform students of university and college events that relate to populations of diversity.

20. Faculty suggestions and help for Euro-American students when needed.

21. Faculty discussion in the classroom that highlights various societal barriers for populations of diversity. 


\section{Student Scale}

22. Segregation by choice of students of diversity within the classroom.

23. Segregation of students by diversity in informal gatherings.

24. Segregation of students by diversity in study groups.

25. Segregation of students by diversity in completing group assignments.

26. Segregation of students by diversity in classroom break-out groups.

27. Willingness among students to speak out in class in addressing stereotypes or discrimination.

28. Acceptance among peers of other students who speak out in class in addressing stereotypes or discrimination.

29.*

30. Concerns among Euro-American students about favorable treatment of students of diversity.

31. Students' behaviors or verbal responses in the classroom that indicate a lack of respect for populations of diversity.

32. Students' use of slang terms when referring to populations of diversity.

33. Students' behaviors toward other students of diversity that indicate a lack of respect for populations of diversity.

34. Students' respect for the importance of course content on diversity in preparation for practice.

35. Students' willingness to discuss differences of opinion related to diversity.

36. Students' interest in facilitating an inclusive environment within the college.

37. Concerns among students of diversity about favorable treatment of Euro-American students.

38. Interest among Euro-American students in getting to know students of diverse populations.

39. Interest among students of diversity in getting to know Euro-American students.

40. Euro-American students' respect for differing points of view about diversity.

41. Respect by students of diversity for differing points of view held by Euro-Americans.

NOTE: Number 29 was duplicated inadvertently and was eliminated from the scale and all analyses.

[This space left blank intentionally] 


\section{References}

1. Allport, G. W. (1954). The Nature of Prejudice. Garden City, NY: Doubleday.

2. Anderson, J. P. (1998). Clinical Social Work Practice with Urban African American Families. Families in Society: The Journal of Contemporary Human Services, 79, 197. Retrieved from Infotrac.

3. Baer, J. (1999). Family Relationships, Parenting Behavior, and Adolescent Deviance in Three Ethnic Groups. Families in Society: The Journal of Contemporary Human Services, 80, 279. Retrieved from Infotrac.

4. Baughan, K. (1992). Student perceptions of the racial climate at Prince George's Community.

5. College (Research Brief RB93-1). Largo, MD: Prince George’s Community College, Office of Institutional Research.

6. Blumer, H. (1955). Reflections on theory of race relations. In A.W. Lind (Ed.), Race relations in world perspective (pp. 3-21). Honolulu: University of Hawaii Press.

7. Blumer, H. (1958). Race prejudice as a sense of group position. Pacific Sociological Review, 1, 3-7.

8. Bobo, L. D. (1999). Prejudice as group position: Microfoundations of a sociological approach to racism and race relations. Journal of Social Issues, 55, 445. Retrieved from Infotrac.

9. $\quad$ Borus, J. F., Stanton, M. D.,\& Doud, A. F. (1972). Racial perceptions in the Army: An approach. American Journal of Psychiatry, 11, 1369-1374.

10. Buchan, V. V. (1991). To assess or not to assess is no longer the question: Potential of program monitoring. Journal of Social Work Education, 27, 25-33.

11. Buford, P. S. (1999). Corporate America's stake in higher education diversity. Black Issues in Higher Education, 16, 128. Retrieved from Infotrac.

12. Carlton-LaNey, I. (1999). African American social work pioneers' response to need. Social Work, 44, 311-321.

13. Carter, C. S. (1997). Using African-centered principles in family-preservation services. Families in Society: The Journal of Contemporary Human Services, 78, 531. Retrieved from Infotrac.

14. Cohen, J. \& Cohen, P. (1983). Applied multiple regression/correlation analysis for the behavioral sciences (2nd ed.). Hillsdale, NJ: Lawrence Erlbaum.

15. Copeland, V. C. (1996). Immunization among African American children: Implications for social work. Health and Social Work, 21, 105. Retrieved from Infotrac.

16. Council on Social Work Education. (1997). Handbook of accreditation standards and procedures. Alexandria, VA: Author.

17. Gant, L. M. (1996). Are culturally sophisticated agencies better workplaces for social work staff and administrators? Social Work, 41, 163. Retrieved from Infotrac.

18. Goodman, H., Getzel, G. S. \& Ford, W. (1996). Group work with high-risk urban youths on probation. Social Work, 41, 375. Retrieved from Infotrac.

19. Green, N. L. (1995). Development of the Perceptions of Racism Scale. IMAGE: Journal of Nursing Scholarship, 27, 141-146.

20. Greif, G. L., Hrabowski, F. A. \& Maton, K. I. (1998). African American fathers of highachieving sons: Using outstanding members of an at-risk population to guide intervention. Families in Society: The Journal of Contemporary Human Services, 79, 45. Retrieved from Infotrac. 
21. Haight,W. L. (1998). "Gathering the spirit" at First Baptist Church: Spirituality as a protective factor in the lives of African American children. Social Work, 43, 213-221.

22. Harvey, A. M. \& Rauch, J. B (1997). A comprehensive Afrocentric rites of passage program for Black male adolescents. Health and Social Work, 22, 30. Retrieved from Infotrac.

23. Herz, R. \& Ferguson, F.I.T. (1996). Childcare choice and constraints in the United States: Social class, race and the influence of family views. Journal of Comparative Family Studies, 27, 249. Retrieved from Infotrac.

24. Hiett, R. L., McBride, R. S. \& Fiman, B. G. (1978). The Racial Attitudes and Perceptions Survey (RAPS) (Technical Paper 338). Monterrey, CA: U.S. Army, Research Institute for the Behavioral and Social Sciences.

25. Hollingsworth, L. D. (1998). Promoting same-race adoption for children of color. Social Work, 43, 104-116.

26. Hudson, W. W. (1982). The clinical measurement package: A field manual. Homewood, IL: Dorsey.

27. Hull, G. H., Mather, J. H., Christopherson, P. M. \& Young, C. M. (1994). Quality assurance in social work education: A comparison of outcome assessments across the continuum. Journal of Social Work Education, 30, 388-396.

28. Kailin, J. (1998). Preparing urban teachers for schools and communities: An anti-racist perspective. High School Journal, 8, 80.

29. Kipp, S. M. (1998). Demographic trends and their impact on the future of the Pell Grant program. Available: http://www.collegeboard.org/policy/html/kipp4.html

30. Lum, D. (1999). Culturally competent practice. Pacific Grove, CA: Brooks/Cole.

31. Mason, J. (1995). Cultural Competence Self-Assessment Questionnaire: A manual for users. Portland, OR: Portland State University, Regional Research for Human Services, Research and Training Center on Family Support and Children's Mental Health.

32. Moghaddam, F. M., Stolkin, A. J.,\&Hutcheson, L. S. (1997). A generalized personal/group discrepancy: Testing the domain specificity of a perceived higher effect of events on one's group than on oneself. Personality and Social Psychology Bulletin, 23, 743-750.

33. Nagel, G. K. (1998). Looking for multicultural education: What could be done and why it isn’t. Education, 119, 253. Retrieved from Infotrac.

34. Nordlie, P. G. \& Thomas, J. A. (1974). Black and White perceptions of the Army's equal opportunity and treatment programs (ARI Technical Paper 252). Alexandria, VA: U.S. Army Research Institute for the Behavioral and Social Sciences.

35. Nunnally, J. C. \& Bernstein, I. H. (1994). Psychometric theory (3rd ed.) New York: McGraw-Hill.

36. Okum, B. F., Fried, J. \& Okum, M. L. (1999). Understanding diversity: A learning-aspractice primer. Pacific Grove, CA: Brooks/Cole.

37. Olson, J. M., Roese, N., Meen, J. \& Robertson, D. J. (1995). The preconditions and consequences of relative deprivation: Two field studies. Journal of Applied Social Psychology, 25, 944-964.

38. Poindexter, C. C. \& Linsk, N. L. (1999). HIV-related stigma in a sample of HIV-affected older female African American caregivers. Social Work, 44, 46. Retrieved from Infotrac.

39. Postmes, T., Branscombe, N. R., Spears, R. \& Young, H. (1999). Comparative processes in personal and group judgments: Resolving the discrepancy. Journal of Personality and Social Psychology, 76, 320-338. 
40. Ruggiero, K. M. (1999). The personal/group discrepancy: Extending Allport's analysis of targets. Journal of Social Issues, 55, 519. Retrieved from Infotrac.

41. Ruggiero, K. M. \& Taylor, D. M. (1994). The personal/group discrimination discrepancy: Women talk about their experiences. Journal of Applied Social Psychology, 24, 1806-1826.

42. Scannapieco, M. \& Jackson, S. (1996). Kinship care: The African American response to family preservation. Social Work, 41, 190. Retrieved from Infotrac.

43. Schiele, J. H. (1996). Afrocentricity: An emerging paradigm in social work practice. Social Work, 41, 284. Retrieved from Infotrac.

44. Siegel, S. \& Castellan, N. J. (1988). Nonparametric statistics for the behavioral sciences ( $2^{\text {nd }}$ ed.), New York: McGraw-Hill.

45. Singelis, T. M. (1998). Teaching about culture, ethnicity, and diversity: Exercises and planned activities. Thousand Oaks, CA: Sage.

46. Stevens, J.W. (1998). A question of values in social work practice: Working with the strengths of Black adolescent females. Families in Society: The Journal of Contemporary Human Services, 79, 288. Retrieved from Infotrac.

47. Stoloff, P. M., Lockman, R. F., Allbritton, A. S. \& McKinley, H. H. (1972). Development of the Navy Human Relations Questionnaire (RC 225). Arlington,VA: Center for Naval Analyses.

48. Swigonski, M. E. (1996). Challenging privilege through Africentric socialwork practice. Social Work, 41, 153. Retrieved from Infotrac.

49. Taylor, D. M., Wright, S. C. \& Porter, L. E. (1994). Dimensions of perceived discrimination: The personal/group discrimination discrepancy. In M. P. Zanna \& J. M. Olson (Eds.), The psychology of prejudice: The Ontario Symposium 7 (pp. 233-255). Hillsdale, NJ: Lawrence Erlbaum.

50. Taylor, D. M., Wright, S. C. \& Ruggiero, K. M. (1991). The personal/group discrimination discrepancy: Responses to experimentally induced personal and group discrimination. Journal of Social Psychology, 13, 847-858.

51. Zanna, M. P., Crosby, F., \& Loewenstein, G. (1987). Male reference groups and discontent among female professionals. In B. A. Gutek\&L. Larwood (Eds.),Women's career development (pp. 28-41). Newbury Park, CA: Sage. 